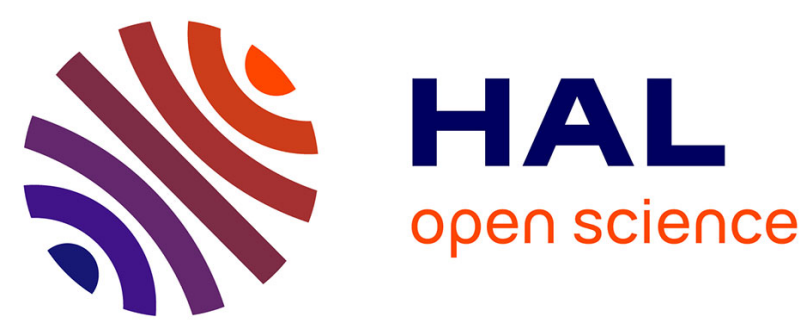

\title{
Metal-free nitrogen-doped graphenic materials as cathode catalysts for the oxygen reduction reaction in polymer electrolyte membrane fuel cells
}

Claire Hérold, Lilian Moumaneix, Sébastien Fontana, François Lapicque

\section{To cite this version:}

Claire Hérold, Lilian Moumaneix, Sébastien Fontana, François Lapicque. Metal-free nitrogen-doped graphenic materials as cathode catalysts for the oxygen reduction reaction in polymer electrolyte membrane fuel cells. Journal of Applied Electrochemistry, 2021, 51 (5), pp.727 - 738. 10.1007/s10800021-01532-6 . hal-03429279

\author{
HAL Id: hal-03429279 \\ https://hal.science/hal-03429279
}

Submitted on 15 Nov 2021

HAL is a multi-disciplinary open access archive for the deposit and dissemination of scientific research documents, whether they are published or not. The documents may come from teaching and research institutions in France or abroad, or from public or private research centers.
L'archive ouverte pluridisciplinaire HAL, est destinée au dépôt et à la diffusion de documents scientifiques de niveau recherche, publiés ou non, émanant des établissements d'enseignement et de recherche français ou étrangers, des laboratoires publics ou privés. 
archives-ouvertes

\title{
Metal-free nitrogen-doped graphenic materials as cathode catalysts for the oxygen reduction reaction in polymer electrolyte membrane fuel cells
}

\author{
Lilian Moumaneix, Sébastien Fontana, Claire Hérold, François Lapicque
}

\section{To cite this version:}

Lilian Moumaneix, Sébastien Fontana, Claire Hérold, François Lapicque. Metal-free nitrogen-doped graphenic materials as cathode catalysts for the oxygen reduction reaction in polymer electrolyte membrane fuel cells. Journal of Applied Electrochemistry, Springer Verlag, 2021, 51 (5), pp.727-738. 10.1007/s10800-021-01532-6 . hal-03407109

\section{HAL Id: hal-03407109 \\ https://hal.archives-ouvertes.fr/hal-03407109}

Submitted on 28 Oct 2021

HAL is a multi-disciplinary open access archive for the deposit and dissemination of scientific research documents, whether they are published or not. The documents may come from teaching and research institutions in France or abroad, or from public or private research centers.
L'archive ouverte pluridisciplinaire HAL, est destinée au dépôt et à la diffusion de documents scientifiques de niveau recherche, publiés ou non, émanant des établissements d'enseignement et de recherche français ou étrangers, des laboratoires publics ou privés. 


\title{
Metal-free nitrogen-doped graphenic materials as cathode catalysts for the oxygen reduction reaction in polymer electrolyte membrane fuel cells
}

\author{
Lilian Moumaneix ${ }^{1,2}$, Sébastien Fontana ${ }^{1}$, Claire Hérold ${ }^{1}$, François Lapicque ${ }^{2, *}$ \\ ${ }^{1}$ Institut Jean Lamour, CNRS - Université de Lorraine, 2 Allée André Guinier, 54000 Nancy, France \\ ${ }^{2}$ Laboratoire Réactions et Génie des procédés, CNRS - Université de Lorraine, 1 rue Grandville, \\ 54000 Nancy, France
}

\begin{abstract}
:
Exhibiting a very high surface area, a good electrical conductivity and a high density of active sites, nitrogendoped graphenic materials are considered as promising catalysts for the oxygen reduction reaction (ORR). Seldom studied in acidic media, $\mathrm{N}$-doped graphenic foams were tested here as the cathode catalysts of a polymer electrolyte membrane fuel cell (PEMFC). The materials were prepared via a solvothermal-based process, by reacting either cyclohexanol and ethanolamine or 1-(2-hydroxyethylethyl)piperidine with metallic sodium, under high pressure and temperature. Membrane electrode assemblies were prepared with a Pt/C anode, 212 Nafion membrane, and an $8 \mathrm{~mm}$ disk cathode based on the graphenic materials. The performance exhibited by the PEMFC was evaluated using chronopotentiometry and impedance spectroscopy, depending on the synthesis conditions. The kinetic parameters of the ORR were estimated by interpretation of the experimental data: the high Tafel slope found might express the partial control of oxygen diffusion through the graphenic microporous structure. Relationships between the electrochemical behavior of the materials and their structural properties are discussed. Moderately crystallized materials with a low oxygen content showed the highest catalytic properties, with a current density larger than $30 \mathrm{~mA} \mathrm{~cm}{ }^{-2}$ and a maximum power density at $2.3 \mathrm{~mW} . \mathrm{cm}^{-2}$.
\end{abstract}

Keywords: N-doped graphenic materials, oxygen reduction reaction, cathode, PEM fuel cells, metal-free catalysts

Correspondence (*): Dr Francois Lapicque

francois.lapicque@univ-lorraine.fr 


\section{Introduction}

In order to meet the demands of the European Union for strong reductions of emissions to combat global warming, the need for more efficient energy systems is critical. $\mathrm{H}_{2}$ fuel cells based systems could provide higher energy efficiency with nearly zero carbon emissions for stationary or transport applications [1]. Up to now, the most efficient catalyst for the sluggish oxygen reduction reaction (ORR) are platinum or platinum-alloy catalysts [2-5]. High market penetration of polymer electrolyte membrane fuel cells (PEMFCs) suffer from their need in platinum-based catalysts. For instance, the $114 \mathrm{~kW}$ fuel cell stack in Toyota's Mirai contains approx. $30 \mathrm{~g}_{\mathrm{Pt}}$. The availability of platinum is subject to environmental, geopolitical and economic factors, carrying a high-risk of primary source disruption [6,7]. Development of alternative critical metal-free catalysts is thus essential for the expansion of $\mathrm{H}_{2}$ fuel cells. Various directions have been explored provide alternative materials e.g. transition metal catalysts and metal-free catalysts.

Thanks to their high stability in agressive environment, their high electrical properties and their adaptable morphology, particular carbon-based materials appear promising metal-free catalysts for ORR. In particular, nitrogen-doped graphenic materials have drawn researchers' attention since their high catalytic activity towards the ORR was demonstrated using density functional theory (DFT) calculations and experimental works [8-11]. $\mathrm{N}$-doped graphenic materials can present higher stability than Pt-based catalyst during operation [12] and the active sites are less subject to poisoning, one of the main limitations of current Pt-based catalysts [13,14]. These recent years, focus on $\mathrm{N}$-doped graphenic materials for ORR has been put on alkaline media, where their catalytic activity can exceed those of platinum-based catalysts [13,15-17]. However, because of the growing use of PEMFCs for transportation applications, studies in acidic media are also needed, even if the ORR remains rate-controlling in such conditions. Upon further progress, N-doped graphenic materials could ultimately provide an alternative to Pt-based catalysts in PEMFCs.

Mechanisms responsible for the ORR activity in N-doped graphenic materials have been highly debated since several critical parameters play a role in this reaction. Nitrogen atoms can be present in five main functions in $\mathrm{N}$ doped carbon materials. First, pyrrolic-N and pyridinic-N are both bonded to two carbon atoms within pentagonal or hexagonal cycles, respectively. Graphitic-N substitutes one carbon atom and is therefore bonded to three carbon atoms inside the graphenic network. Surface functions such as amine or nitrile can also be found, mostly at the edges of the layers. Finally, N-oxides are also present, in the form of pyridine-N-oxide or pyridonic-N [18-19]. DFT calculations showed that mainly graphitic, pyrrolic and pyridinic-N are susceptible to provide catalytic activity towards ORR [8-11]. Besides, Wu et al. [20] demonstrated by DFT that hydrogen peroxide $\mathrm{H}_{2} \mathrm{O}_{2}$ - an undesired intermediate in ORR- can chemically adsorb on the surface of $\mathrm{N}$-graphenic materials containing graphitic, pyrrolic or pyridinic-N in the presence of protons, thus indicating its possible reduction to water. The hypothesis was experimentally confirmed [12-16], showing that $\mathrm{O}_{2}$ is mainly reduced to water through a four-electron reaction.

However, no experimental consensus on the most effective $\mathrm{N}$-function has yet emerged because of the difficulty to obtain comparable materials containing very different proportions of nitrogen functions. Moreover, the chemical nature of the nitrogen-containing groups cannot be controlled during the synthesis.

Common mechanisms suggest that the introduction of nitrogen atoms into the graphenic network modifies the global distribution of spin and charge densities of neighboring carbon atoms, influencing the oxygen adsorption and further electrochemical reactions around nitrogen atoms. While spin density would act on the positional selectivity of radical adsorption, charge density would be responsible for the attractive force between charged atoms. Zhang et al. [8] demonstrated that carbon atoms with a charge density larger than 0.15 were likely to serve as active sites. Guo et al. [21] experimentally established a linear relationship between the current density and the concentration of pyridinic-N. According to the authors, carbon atoms close to pyridinic-N behave as 
Lewis bases owing to the possible electron pair donation. Since $\mathrm{O}_{2}$ is susceptible to adsorb on Lewis bases, neighboring pyridinic-N carbon atoms would be the ORR active sites. Another study [16] suggested that pyridinic- $\mathrm{N}$ facilitates $\mathrm{O}_{2}$ adsorption and eliminates intermediate $\mathrm{H}_{2} \mathrm{O}_{2}$ formation. In contrast, according to Lai et al. [22], graphitic-N species reduce the electron density on adjacent carbon atoms, improving electron transfer from carbon to nitrogen atoms: electron backdonation from nitrogen to adjacent $\mathrm{C}_{\mathrm{pz}}$ orbitals out of the graphenic plan actually facilitates $\mathrm{O}_{2}$ dissociation.

In addition to the direct electronic influence of nitrogen atoms on neighboring carbon atoms, nitrogen species are presumably markers of structural and microstructural changes in the carbon matrix. Parameters such as the size of the $\pi$-conjugated system [21], the pore diameter distribution [23] or the nature of carbon defects [24,25] have been shown to affect the catalytic activity, independent of heteroatom doping. The debate to elucidate which is the most active nitrogen specie could be biased without considering the intrinsic carbon defects present in the material due to the insertion of nitrogen or to the synthesis method. As a matter of fact, the pyrolysis temperature could have a direct impact on the carbon defect content and the $\pi$-conjugated system size. Florent et al. [23] observed that the hydrophobic ultramicropores in the carbon matrix, withdraw oxygen from the electrolyte and promote oxygen bond splitting and ORR. Moreover, pentagon and zigzag edge defects thanks to their specific electronic structures, were shown to be good candidates for ORR from a thermodynamic point of view [24]. Coupling nitrogen-containing catalytic centers to a controlled carbon matrix microstructure seems to be the key to obtain highly performing nitrogen-doped graphenic materials for the ORR.

The present work aims to study the performances for ORR of nitrogen-doped graphenic foams, a material that exhibits very large surface area and various nitrogen functions, in fuel cell operation. Prepared after solvothermal route, the materials have been tested under $\mathrm{H}_{2}$ and air supply in a proton membrane fuel cell, which has not yet been reported in the literature to our state of knowledge. The catalytic efficiency of various N-doped graphenic materials on ORR in a complete fuel cell was measured in terms of voltage versus current density relationship. EIS measurements and voltage monitoring at a fixed current level allowed the kinetic parameters of the cathode reaction with these materials to be estimated. These parameters were then discussed depending on the operating conditions for their synthesis and the physico-chemical properties of these materials.

\section{Experimental}

\subsection{Material synthesis}

Elaboration of the N-doped graphenic materials:

Two sample series were synthesized, differentiated by the initial reagents employed for their synthesis, either a mixture of cyclohexanol and ethanolamine (abbreviated CE series), or 1-(2-hydroxyethyl)piperidine (abbreviated HEP series).

- Elaboration of the CE series materials:

A mixture of $0.1 \mathrm{~mol}$ of cyclohexanol (Sigma Aldrich, 99\%), $0.1 \mathrm{~mol}$ of ethanolamine (Aldrich chemistry, $>99.5 \%$ ) was put in contact with 0.26 mol of metallic sodium (Merck Millipore) under inert atmosphere (nitrogen Air Liquide, alphagaz 2) in a $0.5 \mathrm{~L}$ Parr autoclave. Cyclohexanol and ethanolamine were used as received. Sodium rods were washed in petroleum ether to remove the paraffin oil then cut in small pieces and stored under nitrogen atmosphere. Sodium pieces were scrapped before use to remove the passivation layer that is formed even under protective atmosphere. The autoclave was sealed and nitrogen (Air Liquide, alphagaz 2) was introduced so that the pressure attained 70 bar. The reactor was then heated up to $350{ }^{\circ} \mathrm{C}$ at $8{ }^{\circ} \mathrm{C} \cdot \min ^{-1}$, the internal pressure reached 200 bar, and the mixture was let to react for $72 \mathrm{~h}$. Afterwards, the reaction was allowed 
to cool down naturally to room temperature, and the solvothermal product was collected under nitrogen atmosphere.

About $5 \mathrm{~g}$ of solvothermal product were placed in an Inconel® 600 crucible and then introduced in a vertical tubular oven. Depending on the planned conditions, the oven was heated at a heating rate of $20{ }^{\circ} \mathrm{C} \cdot \mathrm{min}^{-1}$ up to the reaction temperature in the range $750{ }^{\circ} \mathrm{C}-900{ }^{\circ} \mathrm{C}$ for $4 \mathrm{~h}$, then cooled down to room temperature naturally. The crucible was permanently kept under a nitrogen flow (Air Liquide, alphagaz 1) to avoid combustion of the carbonaceous phase and to eliminate pyrolysis gases. The pyrolysis product consisted of a greyish black powder, with in some cases sodium carbonate and sodium hydroxide white crystals.

The pyrolysis product was crushed then sonicated $10 \mathrm{~min}$ in $200 \mathrm{~mL}$ of distilled water. The powder was washed alternatively with $1 \mathrm{~L} 6$ mol.L ${ }^{-1}$ hydrochloric acid (Sigma Aldrich, $\geq 37 \%$ ) and $1 \mathrm{~L}$ distilled water. The initially grey powder turned to black due to the removal of sodium carbonate and sodium hydroxide formed during the pyrolysis. The washed sample was finally dried at $100{ }^{\circ} \mathrm{C}$ for $24 \mathrm{~h}$, and stored under air.

- Elaboration of the HEP series materials:

The elaboration process of the HEP series follows the one described for the CE series, except for the quantities of reagents initially introduced in the solvothermal reactor. $0.17 \mathrm{~mol}$ of 1-(2-hydroxyethyl)piperidine (ACROS organics, 99\%) was introduced inside the solvothermal reactor with 0.34 mol of metallic sodium (Merck Millipore) under nitrogen (Air Liquide, Alphagaz 2). 1-(2-hydroxyethyl)piperidine was used as received. The pressure of nitrogen injected into the reactor and the other experimental parameters remained strictly identical as the CE series.

\subsection{Material characterizations}

Physisorption of nitrogen at $77 \mathrm{~K}$ was performed with a Micromeritics ASAP2020 adsorption apparatus. The samples were outgassed during $12 \mathrm{~h}$ at $300{ }^{\circ} \mathrm{C}$ before analysis. Specific surface areas were calculated using the BET (completed with the Rouquerol correction) and 2D-NLDFT models, micropore volumes and pore size distributions were obtained using 2D-NLDFT model: this model can actually avoid overestimation of the specific surface area by the BET model for microporous solids. 2D-NLDFT calculations were carried out using SAIEUS software, with a corrugation parameter $\lambda=4.25$ and an integration range from $0.4 \mathrm{~nm}$ to $29.3 \mathrm{~nm}$.

X-ray photoelectron spectroscopy (XPS) analysis was achieved with a Kratos Axis Ultra DLD, using an Al K $\alpha 1$ X-ray source (1486.6 eV). C-C and C-H bounds were taken as references at $284.6 \mathrm{eV}$. The analyzed area was of $700 \times 300 \mu \mathrm{m}^{2}$ with a $5-10 \mathrm{~nm}$ depth. Deconvolution of the N1s spectra was carried out considering five contributions, namely pyridinic- $\mathrm{N}$ at $398.3 \mathrm{eV}$, aminic-N at $398.9 \mathrm{eV}$, pyrrolic-N at $400.0 \mathrm{eV}$, graphitic-N at $401.4 \mathrm{eV}$ and N-oxides at $402.4 \mathrm{eV}$. Deconvolution of $\mathrm{O} 1 \mathrm{~s}$ spectra revealed the presence of chemisorbed $\mathrm{O}$ at $531.4 \mathrm{eV}$, carbonyl-O at $532.9 \mathrm{eV}$ and ether or alcohol $\mathrm{O}$ at $535 ; 2 \mathrm{eV}$.

Raman spectroscopy investigations were conducted with a Renishaw inVia Quontor equipped with a $532 \mathrm{~nm}$ laser operating in the spectral range $100-3600 \mathrm{~cm}^{-1}$ in synchroscan mode. Samples were first dispersed in absolute ethanol then deposited on a glass slide.

\subsection{Preparation of the ink and MEAs:}

$16 \mathrm{mg}$ of $\mathrm{N}$-doped graphenic foam were mixed with $50 \mu \mathrm{L}$ of distilled water, $20 \mu \mathrm{L}$ of Nafion ${ }^{\circledR}$ Solution (Nafion ${ }^{\circledR}$ perfluorinated resin, $10 \mathrm{wt} . \%$ in $\mathrm{H}_{2} \mathrm{O}$, Aldrich) and $560 \mu \mathrm{L}$ of 2-propanol (Sigma-Aldrich). The mixture was then stirred at 20,000 rpm for $30 \mathrm{~s}$, before being sonicated for $15 \mathrm{~min}$. The resulting ink was carefully deposited on a $8 \mathrm{~mm}$ disk of Sigracet 34BC GDL. $35 \mu \mathrm{L}$ of ink were deposited on the GDL to prepare a GDE with a catalyst loading of $1.77 \mathrm{mg} \mathrm{cm}^{-2}$. The prepared electrodes were finally dried in an oven at $50{ }^{\circ} \mathrm{C}$ for at 
least 4 hours. The thickness of the deposit has been estimated around $18 \mu \mathrm{m}$, considering an overall density for the carbon material near $1 \mathrm{~g} \mathrm{~cm}^{-3}$, corresponding to a porosity in the order of $50 \%$.

MEAs were prepared by assembling a 40 x $35 \mathrm{~mm}^{2}$ Nafion ${ }^{\circledR}$ membrane (PaxiTech, NR212), a $30 \times 25 \mathrm{~mm}^{2}$ piece of Pt-based GDE (Quintech, Sigracet 10BC, BC-H225-05S, $0.5 \mathrm{mg} \mathrm{cm}^{-2}$ ) on the anodic side, and $30 \times 25$ $\mathrm{mm}^{2}$ piece of GDL Sigracet 34BC. An $8 \mathrm{~mm}$ circular hole had been punched in the rectangular GDL piece, allowing insertion of the above prepared disk for the cathode. The different MEA components were assembled by brushing the coated surface with Nafion solution (Ion Power, water based at $10 \mathrm{wt} . \%$ ) before pressing them onto the membrane at 20 bars. The MEAs formed and still under pressure, were heated up at $100{ }^{\circ} \mathrm{C}$ for 4 min. The resulting MEA and its expanding view are shown in Figure 1.

\subsection{Catalysts electrochemical characterization}

The prepared MEAs were inserted into the $5 \mathrm{~cm}^{2}$ Paxitech fuel cell and tests were carried out at ambient temperature: dry hydrogen was fed at $50 \mathrm{~mL} \mathrm{~min}^{-1}$ and fully humidified air was injected at $100 \mathrm{~mL} \mathrm{~min}^{-1}$ into the cathodic chamber. Hydration and maturation of the MEAs were conducted with increasing gradually the current density for at least two hours for steady, reproducible measurements with a Bio- Logic VSP3 potentiostat.

Steady value of the cell voltage was measured in 30 min long tests at a given current density. Then, galvanostatic electrochemical impedance spectroscopy (GEIS) measurements were carried out at this current density level within the frequency range $10 \mathrm{kHz}-100 \mathrm{mHz}$ with ten points per decade, the amplitude being fixed at $10 \%$ of the steady current. As shown in Figure 2, EIS spectra usually consisted of one very small loop for frequencies larger than $100 \mathrm{~Hz}$ corresponding to the response of the $\mathrm{Pt} / \mathrm{C}$ anode, and a far larger, incomplete loop below 100 $\mathrm{Hz}$ being for the cathode. The profile of spectra led us to model the cell as two (R-CPE) circuits for the anode and the cathode (subscripts a and c respectively), in series with the overall ohmic resistance of the cell, $R_{\text {cell }}$. As a matter of fact, EIS spectra did not allow to consider more complex models, with mass transfer control. Fitting of the spectra led to estimates for charge transfer resistances $R_{a}$ and $R_{c}$, CPE parameters $Q_{a}, n_{a}, Q_{c}, n_{c}$, and $R_{c e l l}$.

The cell voltage $V$ was expressed as follows:

$$
V=V_{0}-R_{\text {cell }} . I-\eta_{a}-\left|\eta_{c}\right|
$$

Where $V_{0}$ is the equilibrium cell voltage, near $1.23 \mathrm{~V}$ at the considered conditions neglecting the contributions of partial pressures in Nernst equation, $I$ the cell current, $\eta_{a}$ and $\eta_{c}$ being the anode and cathode overpotentials respectively. Because the charge transfer resistance of the anode $R_{a}$ has been found nearly constant at $1 \Omega$ within $0.1 \Omega$ for all current values, $\eta_{a}$ was approximated by the product of this resistance and the cell current. The cathode overpotential was expressed after Tafel's law, involving the cathode exchange current density, $i_{0}$, and the Tafel slope, $b$. However, because the cell voltage at open circuit was measured at a value far lower than $V_{0}$, Tafel's law has been modified by addition of "crossover" current density $I_{F C O}$ as follows:

$$
\left|\eta_{c}\right|=\frac{1}{b} \operatorname{Ln}\left(\frac{\left(i+i_{F C O}\right)}{i_{0}}\right)
$$

Therefore, the cell voltage was approximated as:

$$
V \approx V_{0}-\left(R_{\text {cell }}+R_{a}\right) I-\frac{1}{b} \operatorname{Ln}\left(\frac{\left(i+i_{F C O}\right)}{i_{0}}\right)
$$

The specific cathode resistance, $r_{c}$ in $\Omega . \mathrm{cm}^{-2}$, equal to $\left(R_{c} \cdot A\right)$ is defined as the derivative function on of the cathode overpotential with respect to the current density:

$$
r_{c}=\frac{d \eta_{c}}{d i}=\frac{1}{b\left(i+i_{F C O}\right)}
$$


The interpretation of chronopotensiostatic measurements and impedance spectroscopy led to kinetic parameters $b, i_{0}$ and $i_{F C O}$ to be estimated for all the materials tested. For discussion, parameter $b$ was related to the Tafel slope, $m$, by:

$$
m(m V / \text { decade })=\frac{2303}{b}
$$

Finally the equivalent double layer capacitance of the cathode was estimated from parameters $\mathrm{Q}$ and $\mathrm{n}_{\mathrm{c}}$, $\mathrm{using}$ the approximate relationship [26]:

$$
C=Q_{c} \omega_{c}^{n_{c}-1} \sin \left(\frac{n_{c} \pi}{2}\right)\left[1+R_{c} Q_{c} \omega^{n_{c}} \cos \left(\frac{n_{c} \pi}{2}\right)\right]
$$

where $\omega_{\mathrm{c}}$ is the pulsation corresponding to the top of the charge transfer loop in Nyquist plot.

\section{Results and discussions}

Before presenting the results of the present work, properties of CE materials extensively characterized [27] are summarised below. CE materials obtained by pyrolysis at $850^{\circ} \mathrm{C}$ or more, exhibited a high crystallinity, as expressed by narrow bands D and G in Raman spectra. Specific surface area was in the range $1600-2240 \mathrm{~m}^{2} \cdot \mathrm{g}^{-1}$, with microporous volume varying from 0.68 to $1.05 \mathrm{~cm}^{3} . \mathrm{g}^{-1}$, both properties having higher values at 750 and $800^{\circ} \mathrm{C}$. In all $\mathrm{CE}$ materials, pyrrolic-N functions were found to be the most abundant fraction of nitrogen atoms, whereas carbonyl functions were the predominant $\mathrm{O}$-containing groups.

\subsection{Electrochemical measurements}

In a previous work [27], the experimental conditions used for the elaboration of the N-doped graphenic materials have been shown to have a great impact on their textural, structural, microstructural, and chemical properties. In particular, changing the temperature for the pyrolysis treatment allows tailoring of the material properties. In the present study, the catalytic properties of the $\mathrm{N}$-doped graphenic materials have been investigated in regard of the pyrolysis temperature. Moreover, the influence of the change in reagents have also been studied by examining the performance exhibited by CE and HEP series materials.

As a reference, measurements have been carried out on an $\mathrm{N}$-free graphenic material, elaborated under experimental conditions established in a previous study [28]. The maximum power density has been measured at around $0.05 \mathrm{~mW} . \mathrm{cm}^{-2}$, the cell voltage being close to $0.74 \mathrm{~V}$ at $i=0$ but dropping rapidly to reach $0.03 \mathrm{~V}$ at $i=0,8$ $\mathrm{mA} . \mathrm{cm}^{-2}$ (data not shown). This sample will help in understanding the influence of the nitrogen atoms insertion inside the graphenic network on the catalytic activity.

Four pyrolysis temperatures have been studied for the CE series, from $750{ }^{\circ} \mathrm{C}$ to $900{ }^{\circ} \mathrm{C}$, and three for the $\mathrm{HEP}$ series, from $800{ }^{\circ} \mathrm{C}$ to $900{ }^{\circ} \mathrm{C}$. Higher temperatures have not been investigated because of the decreasing variation of the reaction yield with this temperature, found below $1 \mathrm{wt} . \%$ at $900{ }^{\circ} \mathrm{C}$. At $750{ }^{\circ} \mathrm{C}$, the materials were considered too poorly ordered, i.e. with insufficient crystallinity [27] to justify lower pyrolysis temperatures. Moreover, the electric conductivity of samples pyrolyzed at low temperatures was found much lower than that of samples treated at medium/high temperatures in relation to their compared crystallinity, being

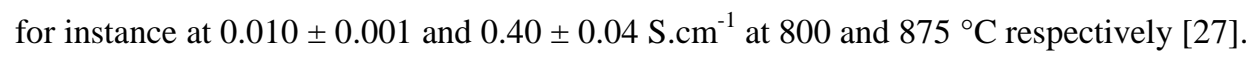

Figure 3 shows the variations of the cell voltage and the power density with the current density, for CE (a) and HEP (b) series materials. Comparable trends can be observed for the two series, i.e. with the highest performances obtained with materials pyrolyzed at the lowest temperatures. In particular, CE-750 appears to be the most promising material with a maximum power density near $2.3 \mathrm{~mW} . \mathrm{cm}^{-2}$ and tolerating a current density larger than $30 \mathrm{~mA} \cdot \mathrm{cm}^{-2}$. HEP series shows lower catalytic activity with a maximum power density at 0.9 $\mathrm{mW} . \mathrm{cm}^{-2}$, and a current density always below $10 \mathrm{~mA} \cdot \mathrm{cm}^{-2}$. The two maximum power densities are respectively 46 times and 18 times higher than the one of $\mathrm{N}$-free graphenic material. 
The ohmic resistance $R_{\text {cell }}$ deduced from the impedance spectra was always in the range $0.15-0.25 \Omega$ : this value although significant is mainly due to the small area of the cathode (approx. $0.5 \mathrm{~cm}^{2}$ ). Nevertheless, considering the current produced by the cell, the ohmic drop was always below $2.5 \mathrm{mV}$. Moreover, the anode overpotential estimated from $R_{a}$ was below $15 \mathrm{mV}$ in all cases, thus the deviation of the cell voltage to the equilibrium voltage corresponds fairly well to the cathode overpotential, including the effect of fuel crossover. The overall cathode resistance $R_{c}$ varied from 7 to $380 \Omega$, depending on the current density and the material evaluated. Finally, exponent $\mathrm{n}$ of the constant phase element lay in the range 0.69-0.75, a range slightly lower than that usually observed with Pt-based catalysts. The equivalent capacitance $\mathrm{C}$ deduced from rel. (6) for the various materials at their maximal performance, varied from 0.015 to $0.23 \mathrm{~F} . \mathrm{cm}^{-2}$. Interestingly, the max power of the cell appears to be a linear function of the equivalent capacitance within $25 \%$ as shown in Figure 4.

The fuel crossover, expressed as its corresponding current density $\mathrm{i}_{\mathrm{FCO}}$ as in relation (2), was in the order of 0.01 $-0.1 \mathrm{~mA} . \mathrm{cm}^{-2}$. The higher value found for CE-800 near $1 \mathrm{~mA} . \mathrm{cm}^{-2}$, may be due to a defect in the membrane electrode assembly which drastically limited its open circuit voltage at $0.42 \mathrm{~V}$.

The values for the exchange current density $i_{0}$, obtained from combined interpretation of impedance spectra and the $V$ vs. $i$ curves using relations (2) and (3), are in accordance with the cell performances, varying from $2.10^{-3}$ mA.cm ${ }^{-2}$ for sample CE-750, to $4.10^{-5} \mathrm{~mA} . \mathrm{cm}^{-2}$ for sample CE-900 (cf. Figure 5 (a)). Similar trend is observed for the HEP series. The compared reactivity of the materials are to be linked to their physicochemical properties: these aspects are further discussed in Section 3.2.

Tafel parameter $b$ was found to be an increasing function of the pyrolysis temperature (Figure 5 (b)) for both series of materials, being near $8.3 \mathrm{~V}^{-1}$ at $750^{\circ} \mathrm{C}$, and $10.8 \mathrm{~V}^{-1}$ at $900^{\circ} \mathrm{C}$. Kinetic parameters $i_{0}$ and $b$ follow opposite variations with the pyrolysis temperature, parameter $b$ dampening the very strong effect of $i_{0}$ values exhibited by CE-750 and CE-900 materials. Using relation (2), the current density to be delivered by the cell for an overpotential chosen arbitrarily at $800 \mathrm{mV}$ varies only by a factor 7 between CE-750 and CE-900 materials (Table 1). The maximal power density allowed by the N-doped graphenic materials followed comparable decreasing trends with the increase in pyrolysis temperature (Figure 5 (c)).

Besides, values for $b$ correspond to Tafel slopes varying from 277 to $213 \mathrm{mV} \cdot \mathrm{dec}^{-1}$, values approximately two times larger than those usually accepted for oxygen reduction on Pt surfaces in acidic media, ideally near 118 $\mathrm{mV} \cdot \mathrm{dec}^{-1}$ at $25^{\circ} \mathrm{C}$. The strong difference may originate from the very different nature of the catalytic sites; however, Liu et al. [29] reported a $120 \mathrm{mV} \cdot \mathrm{dec}^{-1}$ Tafel slope for the reduction of dissolved oxygen in $0.1 \mathrm{M}$ $\mathrm{HClO}_{4}$ on their $\mathrm{N}$-graphene. Mass transfer control from dioxygen transfer in the catalytic layer could provide another explanation: when diffusion becomes the rate-determining step inside this layer, the Tafel slope was shown to be doubled from the calculated one without diffusion control [30,31]. At ambient temperature, the theoretical Tafel slope for the ORR on Pt surfaces under mass transfer control would be near $236 \mathrm{mV} \cdot \mathrm{dec}^{-1}$.

The resistance at the cathode determined by impedance spectroscopy would then cover combined controls of the reduction rate by diffusion of oxygen to the $\mathrm{N}$-functions and by charge transfer. Improvement of the MEA preparation, in particular through thinner and more regular catalytic layer and optimized addition of PTFE solution may allow substantial enhancement of the cathode performance by hindering mass transfer control.

\subsection{Correlation with physicochemical properties}

The electrochemical properties of the two material series described above, were compared to other physicochemical properties, e.g. textural properties, crystallinity or chemical composition, to extract pertinent correlations helping to understand which critical parameters should be optimized in order to increase the catalytic activity towards the ORR. Only the CE series has been treated here, since these materials have been extensively characterized [27] and because the electrochemical behavior of the two series appeared similar. 


\subsubsection{Textural properties}

If the evolution of the maximum power density allowed by one material appears correlated with its specific surface area (Figure 6), the data corresponding to CE-750 diverges. In their work, Byambasuren et al. [32] showed that in the case of $\mathrm{N}$-doped mesoporous carbon materials promoted with $1.5 \%$ of iron, the smallest pores allowed highest mass transfer rates due to the higher surface area, and therefore leading to highest MEA performances. However, in their materials, pores were mainly wider than $4.1 \mathrm{~nm}$, for which gas diffusion although hindered by Knudsen effect, can be effective. In the present case, the pore sizes reported in [27], are far smaller, with bimodal distributions, being in the ranges 0.5-1.1 and 1.2-2.0 nm for CE-750 and CE-800, and 0.71.2 and 1.3-2.8 nm for CE-900 material. Because the overall cell performance depends on both the specific area and effectiveness of gas transfer, it might be postulated that diffusion in very small pores, i.e. below $1 \mathrm{~nm}$ becomes more rate controlling, the beneficial effect of the pyrolysis temperature on the specific area being annihilated by the more sluggish diffusion in materials CE-750 and CE-800. This hypothesis appears to be in accordance with the lower $b$ values i.e. the larger Tafel slopes, observed with these materials than with CE-850 or CE-900. Nevertheless, the above attempts in interpreting the data in Figure 6 do not explain the significantly higher performance of CE-750, so the effects of other factors have to be investigated.

\subsubsection{Carbon phase crystallinity}

Crystallinity of graphenic materials is an uneasy parameter to quantify. Nonetheless, Raman spectroscopy analysis can provide general trends on this property. Figure 7 (a) reports the variation of the maximum power density with the intensity of the defects bands D', T and F. The D' band at $1620 \mathrm{~cm}^{-1}$ is associated with defects in the graphene basal plans and can be clearly identified in the case of a limited amount of defects [33]. Bands T and $\mathrm{F}$ observed near $1100 \mathrm{~cm}^{-1}$ and $1500 \mathrm{~cm}^{-1}$ respectively [34, 35] can be attributed to the amorphous carbon fraction, hydrocarbon molecules or aliphatic molecules bound to the graphitic material [36, 37]. These observations are perfectly consistent with Jiang's [24] conclusions on the positive effect of pentagons and zigzag edge defects on graphene efficiency for ORR.

The increase in the intensity of the defects bands goes along with an increase in the catalytic performance of the MEA. This trend could be explained by a higher reactivity of the amorphous regions or by an augmentation of the tortuosity inside the carbon materials, $\mathrm{sp}^{3}$ carbon atoms disrupting the linearity of the $\mathrm{sp}^{2}$ carbon sheets due to the different angle between atoms, or by a higher reactivity of the amorphous regions. These observations tend to be confirmed by the variation of $G$ and $G^{\prime}$ bands intensities, emerging around $1580 \mathrm{~cm}^{-1}$ and $2700 \mathrm{~cm}^{-1}$ respectively (data not shown) and respectively linked to the presence of $\mathrm{sp}^{2}$ carbon atoms and high order in the graphene network [38]. Moreover, G' band is often considered as a marker for local order, its low significance expressing poor order in stacking of single graphene sheets. The highest power densities of the fuel cell were measured for the lowest intensities of G and G' bands (Figure 7 (b)), confirming that amorphous carbon fractions can increase the catalytic properties.

\subsubsection{Chemical composition}

The chemical composition of the elaborated materials is also an important parameter to be considered in examining the electrochemical properties. The atomic amounts of carbon, nitrogen and oxygen elements measured by XPS are presented in Figure 8. Since the penetration depth of the light beam is estimated around 5$10 \mathrm{~nm}$, the results can be considered as corresponding to the "bulk" graphenic material, assuming a thickness of the graphenic walls in the range of 3-6 nm, corresponding to the stacking of 10 to 20 graphene layers, as found for $\mathrm{N}$-free graphenic foams [28].

The power density is clearly correlated with the oxygen atomic amount in the samples, the highest power density being measured for the lowest amount of oxygen, namely CE-750 (Figure 8 (a)). This observation shows that oxygen-containing groups have a detrimental influence on the ORR with our $\mathrm{N}$-doped graphenic foams. The 
evolution of power density also tends to follow the carbon atom concentration (Figure 8 (b)). It appears logical to link the increase in carbon atoms with an increase in the number of active sites, resulting in higher performances for the MEA. Nevertheless, since oxygen is the second most abundant element in the studied materials, high carbon quantities correspond to lower oxygen quantities, and therefore to higher power densities.

On the other hand, nitrogen atomic quantity does not seem to have a clear influence on the measured power density (Figure 8 (c)). In the domain studied, ranging from 0.8 to 2.3 at. $\%$, high doping rates do not appear as necessary to allow good catalytic properties. However, it must be noted that the presence of nitrogen atoms inside the graphenic network is required to observe significant catalytic activity towards the ORR since the $\mathrm{N}$-free graphenic material presents only extremely low activity. The atomic quantity of the three main nitrogen functions, i.e. pyridinic-N, pyrrolic-N and graphitic-N, have been extracted from deconvolutions of XPS N1s spectra. Their variations with the power density are plotted in Figure 9.

None of the $\mathrm{N}$-function contents shows a correlation with the power density, since these parameters change with the oxygen content and the density of defects in the carbon network, which have a greater impact on the electrochemical performances. However, the synthesis method used to obtain the 3D N-doped graphenic materials does not yet allow efficient control of nitrogen doping, so that separate benefits from one specific $\mathrm{N}$ function could not be evidenced in the present study.

\section{Conclusion}

The catalytic activity towards the ORR of N-doped carbon materials, although widely studied in the literature, is rarely evaluated in real condition tests inside a PEMFC. In this work, 3-dimensional N-doped graphenic materials have been inserted inside MEAs as cathodic catalysts for investigation of their intrinsic electrochemical properties. Electrochemical impedance spectroscopy measurements have been modeled using a Randles equivalent circuit in order to extract pertinent information yielding estimates for the exchange current density and Tafel slopes, by using voltage vs. current density variations. Moreover, the max. power allowed by the fuel cell appears to vary linearly to the equivalent capacitance of the cathode.

Comparison between $\mathrm{N}$-doped and $\mathrm{N}$-free graphenic materials clearly shows the beneficial impact of the chemical modification on the ORR catalytic activity, with a nearly 46-fold higher activity with N-doped materials. Regardless of the solvothermal precursor, the electrochemical performances are closely linked to the pyrolysis temperature, the lowest temperatures, $750-800{ }^{\circ} \mathrm{C}$, leading to the highest catalytic activities. The differences observed between the CE and HEP series let us think that significant improvements could be obtained from the research of an optimal solvothermal precursor.

Even if the catalytic activity of $\mathrm{N}$-doped graphenic materials in acidic fuel cells remains far below that of commercial Pt-based catalysts, several routes for improvement have been identified. Electrochemical performances could be linked to the textural properties of the materials since these exhibiting the highest surface areas possess the highest amount of active sites. The structural defects in the graphenic network seem to play an important part in the catalytic properties, even if their exact nature has still to be found. Nitrogen doping has been revealed necessary to bring out the catalytic properties towards the ORR, although its quantity seems to have no clear influence on the MEAs performances. On the other hand, the quantity of oxygen atoms has been shown to influence negatively the ORR reaction. Chemical reduction of the $\mathrm{N}$-graphene materials by hydrazine [39] or ammonia [40] - similar in its principle to the reduction of graphene oxide - could be used to improve this parameter, and increase the quantity of nitrogen doping. Besides, the protocol for MEA preparations could be greatly improved, with thinner but more regular catalyst layers, and more effective dispersion of Nafion on the catalyst to reduce the significance of internal oxygen diffusion control, resulting in larger $b$ parameter values, 
then in higher power density. Finally, for other applications, other MEAs could be prepared with alkaline ionomers, for which higher cell performances could be expected.

\section{Acknowledgements}

This work was partly supported by the French PIA project "Lorraine Université d'Excellence", reference ANR-15-IDEX-04-LUE.

\section{References}

[1] Gröger O, Gasteiger HA, Suchsland J-P (2015) Review-Electromobility: Batteries or Fuel Cells? J. Electrochem. Soc. 162: 2605-2622. https://doi.org/10.1149/2.0211514jes.

[2] Karan HI, Sasaki K, Kuttiyiel K, Farberow CA, Mavrikakis M, Adzic RR (2012) Catalytic Activity of Platinum Monolayer on Iridium and Rhenium Alloy Nanoparticles for the Oxygen Reduction Reaction. ACS Catal. 2: 817-824. https://doi.org/10.1021/cs200592x.

[3] Zhang G, Shao Z-G, Lu W, Li G, Liu F, Yi B (2012) One-pot synthesis of Ir@ Pt nanodendrites as highly active bifunctional electrocatalysts for oxygen reduction and oxygen evolution in acidic medium. Electrochem. Commun. 22: 145-148. https://doi.org/10.1016/j.elecom.2012.05.030.

[4] Zhu H, Zhang S, Guo S, Su D, Sun S (2013) Synthetic control of FePtM nanorods (M = Cu, Ni) to enhance the oxygen reduction reaction. J. Am. Chem. Soc. 135: 7130-7133. https://doi.org/10.1021/ja403041g.

[5] Mani P, Srivastava R, Strasser P (2008) Dealloyed Pt-Cu Core-Shell Nanoparticle Electrocatalysts for Use in PEM Fuel Cell Cathodes. J. Phys. Chem. C 112: 2770-2778. https://doi.org/10.1021/jp0776412.

[6] Robinson Z (2017) Sustainability of platinum production in South Africa and the dynamics of commodity pricing. Resour. Policy 51: 107-114. https://doi.org/10.1016/j.resourpol.2016.12.001.

[7] Government publishing office (2018) Mineral commodities summary 2018. (US Govt. Printing Office).

[8] Zhang Y, Ge J, Wang L, Wang D, Ding F, Tao X, Chen W (2013) Manageable N-doped Graphene for High Performance Oxygen Reduction Reaction. Sci. Rep. 3. https://doi.org/10.1038/srep02771.

[9] Zhang L, Xia Z (2011) Mechanisms of Oxygen Reduction Reaction on Nitrogen-Doped Graphene for Fuel Cells. J. Phys. Chem. C 115: 11170-11176. https://doi.org/10.1021/jp201991j.

[10] Zhang L, Niu J, Dai L, Xia Z (2012) Effect of Microstructure of Nitrogen-Doped Graphene on Oxygen Reduction Activity in Fuel Cells. Langmuir 28: 7542-7550. https://doi.org/10.1021/la2043262.

[11] Duan J, Chen S, Jaroniec M, Qiao SZ (2015) Heteroatom-Doped Graphene-Based Materials for EnergyRelevant Electrocatalytic Processes. ACS Catal. 5: 5207-5234. https://doi.org/10.1021/acscatal.5b00991.

[12] Ma R, Ren X, Xia BY, Zhou Y, Sun C, Liu Q, Liu J, Wang J (2016) Novel synthesis of N-doped graphene as an efficient electrocatalyst towards oxygen reduction. Nano Res. 9: 808-819. https://doi.org/10.1007/s12274015-0960-2.

[13] Shao Y, Zhang S, Engelhard MH, Li G, Show G, Wang Y, Liu J, Aksay IA, Lin Y (2010) Nitrogen-doped graphene and its electrochemical applications. J. Mater. Chem. 20: 7491-7496. https://doi.org/10.1039/c0jm00782j.

[14] Song C (2002) Fuel processing for low-temperature and high-temperature fuel cells Challenges, and opportunities for sustainable development in the 21 st century. Catal. Today 77: 17-49. https://doi.org/10.1016/S0920-5861(02)00231-6. 
[15] Huang J, Han J, Gao T, Zhang X, Li J, Li Z, Xu P, Song B (2017) Metal-free nitrogen-doped carbon nanoribbons as highly efficient electrocatalysts for oxygen reduction reaction. Carbon 124: $34-41$. https://doi.org/10.1016/j.carbon.2017.08.033.

[16] Geng D, Chen Y, Chen Y, Li Y, Li R, Sun X, Ye S, Knights S (2011) High oxygen-reduction activity and durability of nitrogen-doped graphene. Energy Environ. Sci. 4: 760-764 https://doi.org/10.1039/c0ee00326c.

[17] Qu L, Liu Y, Baek J-B, Dai L (2010) Nitrogen-Doped Graphene as Efficient Metal-Free Electrocatalyst for Oxygen Reduction in Fuel Cells. ACS Nano 4: 1321-1326. https://doi.org/10.1021/nn901850u.

[18] Inagaki M, Toyoda M, Soneda Y, Morishita T (2018) Nitrogen-doped carbon materials. Carbon 132: 104140. https://doi.org/10.1016/j.carbon.2018.02.024.

[19] Quílez-Bermejo J, González-Gaitán C, Morallón E, Cazorla-Amorós D (2017) Effect of carbonization conditions of polyaniline on its catalytic activity towards ORR. Some insights about the nature of the active sites. Carbon 119: 62-71. https://doi.org/10.1016/j.carbon.2017.04.015.

[20] Wu P, Du P, Zhang H, Cai C (2013) Microscopic effects of the bonding configuration of nitrogen-doped graphene on its reactivity toward hydrogen peroxide reduction reaction. Phys. Chem. Chem. Phys. 15: 69206928. https://doi.org/10.1039/c3cp50900a.

[21] Guo D, Shibuya R, Akiba C, Saji S, Kondo T, Nakamura J (2016) Active sites of nitrogen-doped carbon materials for oxygen reduction reaction clarified using model catalysts. Science 351: 361-365. https://doi.org/10.1126/science.aad0832.

[22] Lai L, Potts JR, Zhan D, Wang L, Poh CK, Tang C, Gong H, Shen Z, Lin J, Ruoff RS (2012) Exploration of the active center structure of nitrogen-doped graphene-based catalysts for oxygen reduction reaction. Energy Environ. Sci. 5: 7936-7942. https://doi.org/10.1039/c2ee21802j.

[23] Florent M, Wallace R, Bandosz TJ (2019) Oxygen Electroreduction on Nanoporous Carbons: Textural Features vs Nitrogen and Boron Catalytic Centers. ChemCatChem 11: 851-860. https://doi.org/10.1002/cctc.201801675.

[24] Jiang Y, Yang L, Sun T, Zhao J, Lyu Z, Zhuo O, Wang X, Wu Q, Ma J, Hu Z (2015) Significant Contribution of Intrinsic Carbon Defects to Oxygen Reduction Activity. ACS Catal. 5: 6707-6712. https://doi.org/10.1021/acscatal.5b01835.

[25] Ikeda T, Boero M, Huang S-F, Terakura K, Oshima M, Ozaki J-I (2008) Carbon Alloy Catalysts: Active Sites for Oxygen Reduction Reaction. J. Phys. Chem. C 112: 14706-14709. https://doi.org/10.1021/jp806084d.

[26] Franck-Lacaze L, Bonnet C, Choi E, Moss J, Pontvianne S, Poirot H, Datta R, Lapicque F (2009) Ageing of PEMFCs due to operation at low current density: investigation of oxidative degradation, Int. J. Hydrogen Energy 34: 10472-10481. DOI: 10.1007/s10800-012-0451-z

[27] Moumaneix L, Fontana S, Dossot M, Lapicque F, Hérold C (2020) Nitrogen-doped graphenic foam synthesized by solvothermal-based process: Effect of pyrolysis temperature on the material properties. Microporous and Mesoporous Materials 300. https://doi.org/10.1016/j.micromeso.2020.110165.

[28] Speyer L, Fontana S, Cahen S, Ghanbaja J, Medjahdi G, Hérold C (2015) Multi-scale characterization of graphenic materials synthesized by a solvothermal-based process: Influence of the thermal treatment. Solid State Sci. 50: 42-51 https://doi.org/10.1016/j.solidstatesciences.2015.10.009.

[29] Liu J, Sasaki K, Lyth SM (2013) Electrochemical oxygen reduction on metal-free nitrogen-doped graphene foam in acidic media. ECS Transactions 58: 1529-1540. https://doi.org/10.1149/05801.1529ecst. 
[30] Perry ML, Newman J, Cairns EJ (2019) Mass Transport in Gas- Diffusion Electrodes: A Diagnostic Tool for Fuel- Cell Cathodes. J. Electrochem. Soc. 145: 5-15. https://doi.org/10.1149/1.1838202.

[31] Tant S, Rosini S, Thivel P-X, Druart F, Rakotondrainibe A, Geneston T, Bultel Y (2014) An algorithm for diagnosis of proton exchange membrane fuel cells by electrochemical impedance spectroscopy. Electrochimica Acta 135: 368-379. https://doi.org/10.1016/j.electacta.2014.04.108.

[32] Byambasuren U, Jeon Y, Altansukh D, Ji Y, Shul Y-G (2016) The particle size effect of N-doped mesoporous carbons as oxygen reduction reaction catalysts for PEMFC. Korean J. Chem. Eng. 33: 1831-1836. https://doi.org/10.1007/s11814-016-0030-9.

[33] Eckmann A, Felten A, Mishchenko A, Britnell L, Krupke R, Novoselov KS, Casiraghi C (2012) Probing the Nature of Defects in Graphene by Raman Spectroscopy. Nano Lett. 12: 3925-3930. https://doi.org/10.1021/nl300901a.

[34] Piscanec S, Mauri F, Ferrari AC, Lazzeri M, Robertson J (2005) Ab initio resonant Raman spectra of diamond-like carbons. Diam. Relat. Mater. 14: 1078-1083. https://doi.org/10.1016/j.diamond.2004.11.043.

[35] Bhaumik A, Haque A, Taufique M, Karnati P, Patel R, Nath M, Ghosh K (2017) Reduced Graphene Oxide Thin Films with Very Large Charge Carrier Mobility Using Pulsed Laser Deposition. J. Mater. Sci. Eng. 06. https://doi.org/10.4172/2169-0022.1000364.

[36] Smith MW, Dallmeyer I, Johnson TJ, Brauer CS, McEwen J-S, Espinal JF, Garcia-Perez M (2016) Structural analysis of char by Raman spectroscopy: Improving band assignments through computational calculations from first principles. Carbon 100: 678-692. https://doi.org/10.1016/j.carbon.2016.01.031.

[37] Bokobza L, Bruneel J-L, Couzi M (2015) Raman Spectra of Carbon-Based Materials (from Graphite to Carbon Black) and of Some Silicone Composites. Carbon 1: 77-94. https://doi.org/10.3390/c1010077.

[38] Dresselhaus MS, Jorio A, Saito R (2010) Characterizing Graphene, Graphite, and Carbon Nanotubes by Raman Spectroscopy. Annu. Rev. Condens. Matter Phys. 1: 89-108. https://doi.org/10.1146/annurevconmatphys-070909-103919.

[39] Park S, Hu Y, Hwang JO, Lee E-S, Casabianca LB, Cai W, Potts JR, Ha H-W, Chen S, Oh J, Kim SO, Kim Y-H, Ishii Y, Ruoff RS (2012) Chemical structures of hydrazine-treated graphene oxide and generation of aromatic nitrogen doping. Nature Communications 3. https://doi.org/10.1038/ncomms1643.

[40] Zhu Y, Huang H, Zhou W, Li G, Liang X, Guo J, Tang S (2017) Low temperature reduction of graphene oxide film by ammonia solution and its application for high-performance supercapacitors. J. Mater. Sci. Mater. Electron. 28: 10098-10105. https://doi.org/10.1007/s10854-017-6771-3. 
Table 1: Calculated values of the $\mathrm{i}_{0} / \mathrm{i}_{0\left(900{ }^{\circ} \mathrm{C}\right)}$ and $\mathrm{i} / \mathrm{i}_{\left(900{ }^{\circ} \mathrm{C}\right)}$ ratios for an $800 \mathrm{mV}$ overvoltage

\begin{tabular}{cccccc}
\hline Sample ID & $\begin{array}{c}\mathrm{i}_{0} \\
\left(\mathrm{~mA} \mathrm{~cm}^{-2}\right)\end{array}$ & $\begin{array}{c}\text { Tafel's factor b } \\
\left(\mathrm{V}^{-1}\right)\end{array}$ & $\begin{array}{c}\mathrm{i} \text { at }\left|\eta_{\mathrm{C}}\right|=800 \mathrm{mV} \\
\left(\mathrm{mA} \mathrm{cm}^{-2}\right)\end{array}$ & $\begin{array}{c}\left.\mathrm{i}_{0} / \mathrm{i}_{0(900}{ }^{\circ} \mathrm{C}\right) \\
\text { ratio }\end{array}$ & $\begin{array}{c}\left.\mathrm{i} / \mathrm{i}_{(900}{ }^{\circ} \mathrm{C}\right) \\
\text { ratio }\end{array}$ \\
\hline CE-750 & $210^{-3}$ & 8.3 & 1.5 & 55 & 7 \\
CE-800 & $610^{-4}$ & 9.1 & 0.8 & 15 & 4 \\
CE-850 & $110^{-4}$ & 10.4 & 0.4 & 3 & 2 \\
CE-900 & $410^{-5}$ & 10.9 & 0.2 & 1 & 1 \\
\hline \hline HEP-800 & $210^{-4}$ & 9.6 & 0.4 & 3 & 7 \\
HEP-850 & $310^{-5}$ & 10.7 & 0.1 & 1 & 1 \\
HEP-900 & $110^{-5}$ & 10.9 & 0.1 & & 2 \\
\hline
\end{tabular}

\section{Figure caption}

Fig. 1 View of a typical MEA, left with the disk cathode

Fig. 2 EIS spectrum of the MEA prepared from CE materials at $30 \mathrm{~mA} \mathrm{~cm}^{-2}$

Fig. 3 Variation of cell voltages and power densities with the current density of N-doped graphenic materials obtained for different pyrolysis temperatures; CE series (a), HEP series (b)

Fig.4 Variation of the maximum power density of the fuel cell with the equivalent capacitance of the HEP and CE graphenic cathodes

Fig. 5 Variation of the exchange current density (a), the Tafel's factor b (b) and the maximum power density (c) with the pyrolysis temperature

Fig. 6 Variation of the maximum power density with the specific surface area

Fig. 7 Variation of the maximum power density with the Raman defects bands D', T and F (a) and the G and G' bands (b). Trend lines have been added for the sake of clarity.

Fig. 8 Variation of the maximum power density with the atomic quantities of oxygen (a), carbon (b) and nitrogen (c)

Fig. 9 Variation of the maximum power density with the atomic quantities of N-Pyridinic (a), N-Pyrrolic (b) and $\mathrm{N}$-Graphitic (c) 

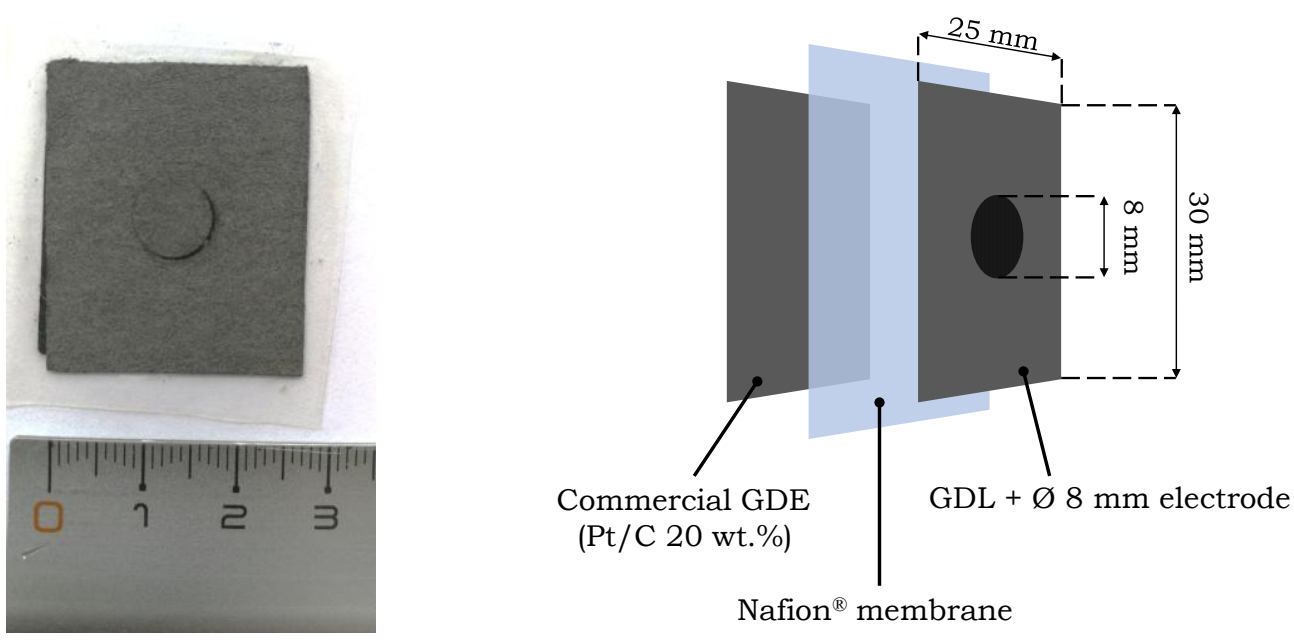

Figure 1

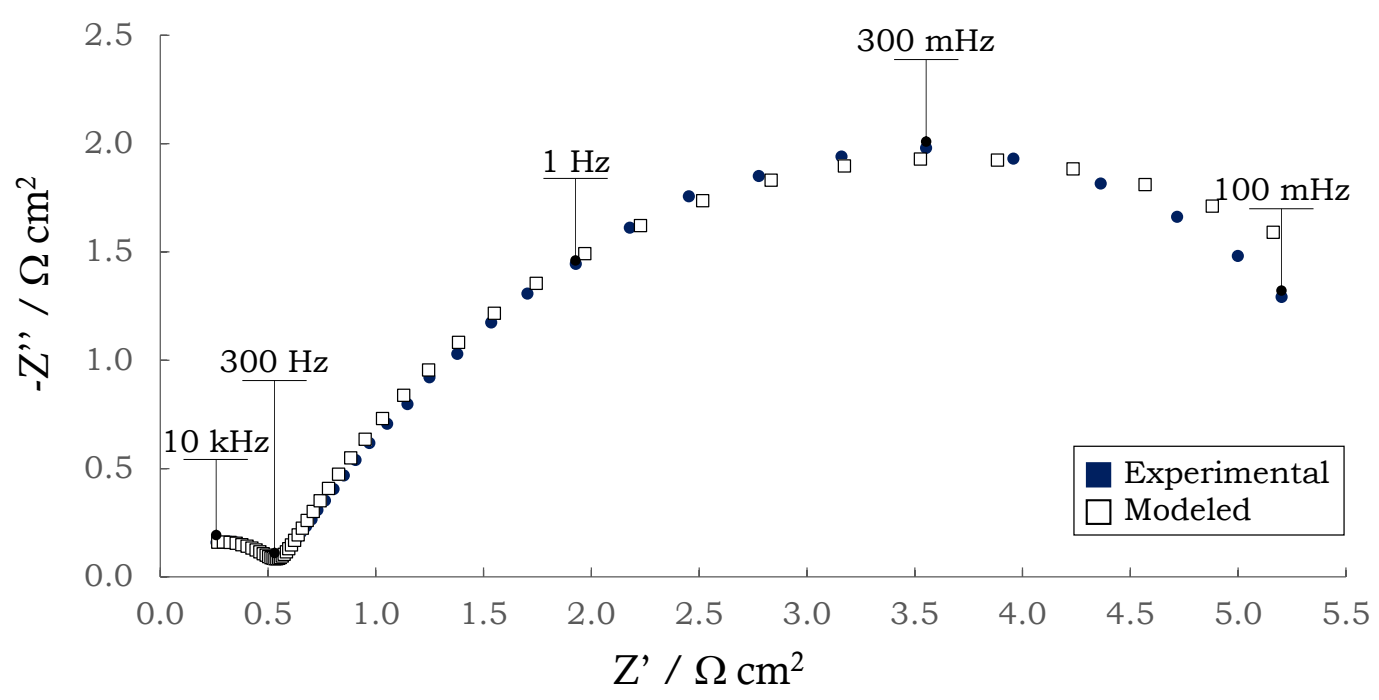

Figure 2
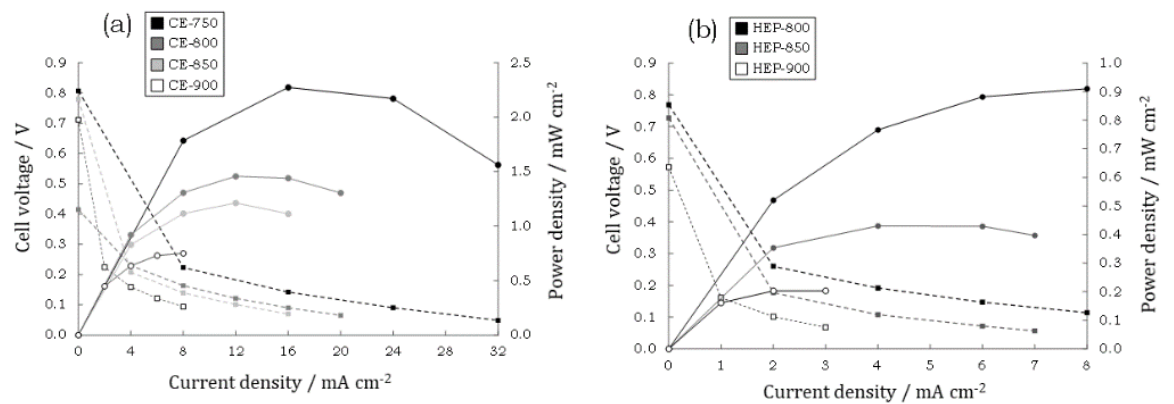

Figure 3 


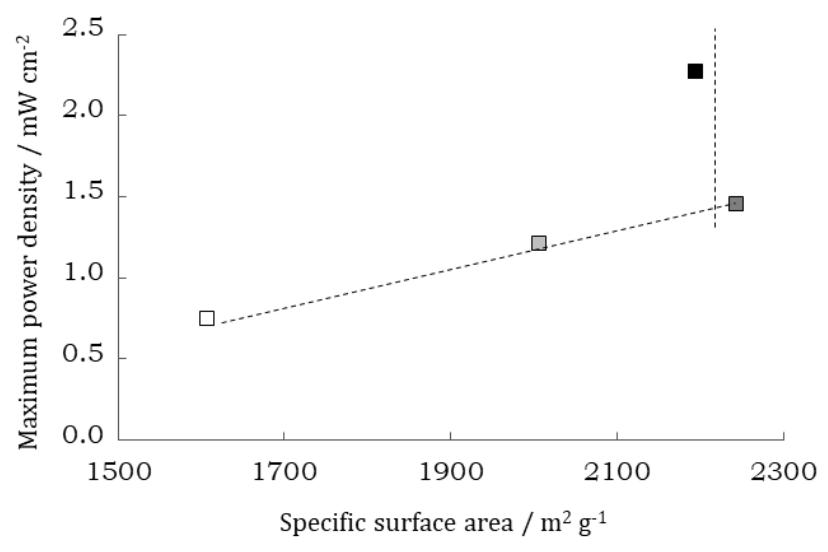

CE-750 $\square \mathrm{CE}-800 \square \mathrm{CE}-850 \square \mathrm{CE}-900$

\section{Figure 4}

(a)

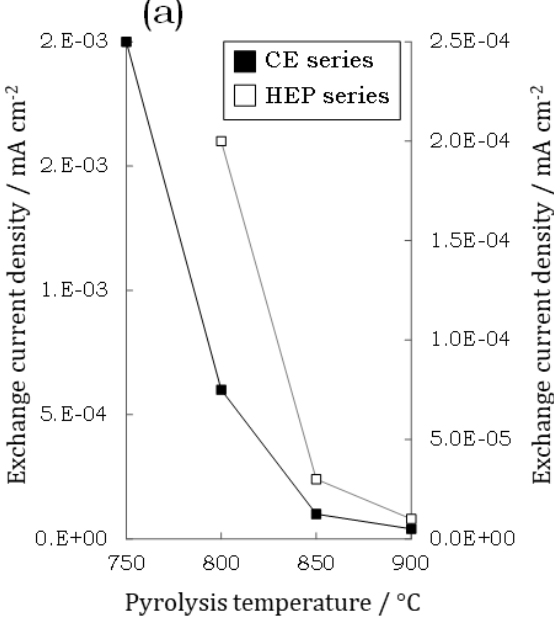

Figure 7

(a)

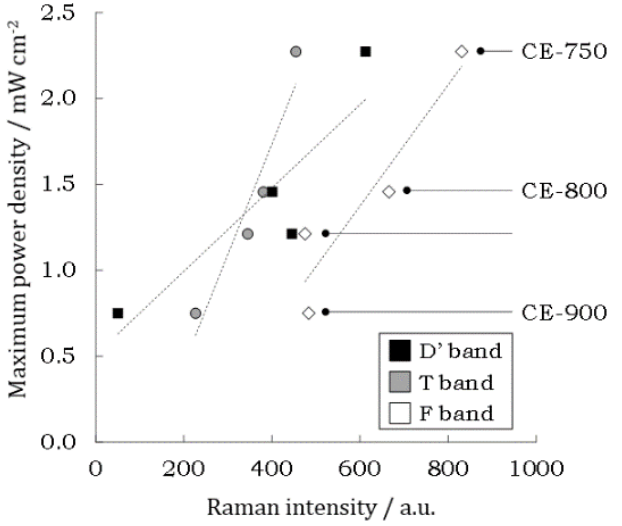

(b)

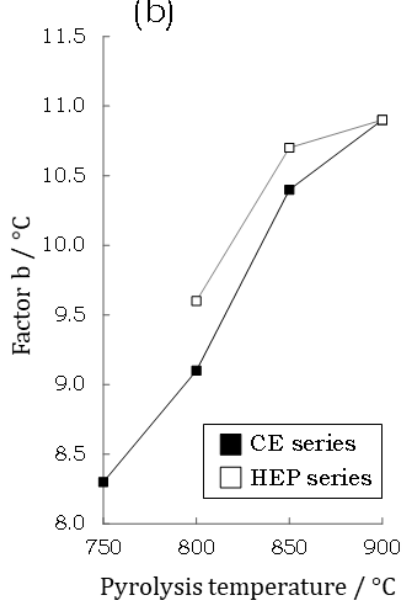

(c)

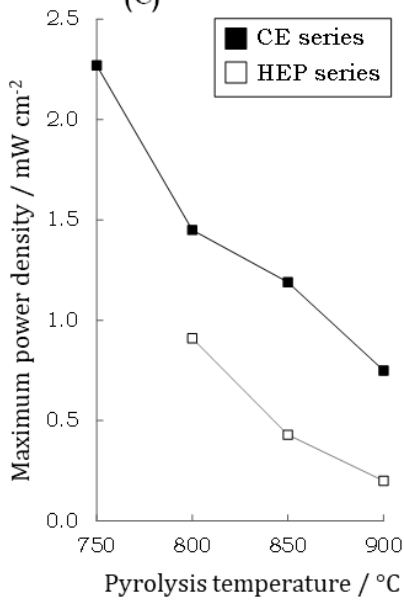

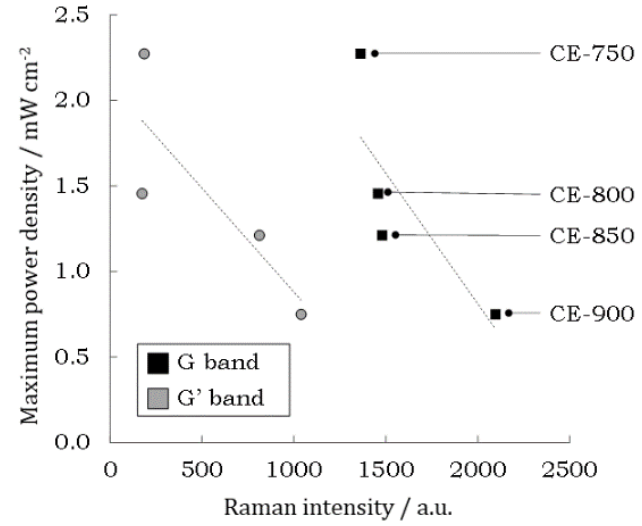


(a)

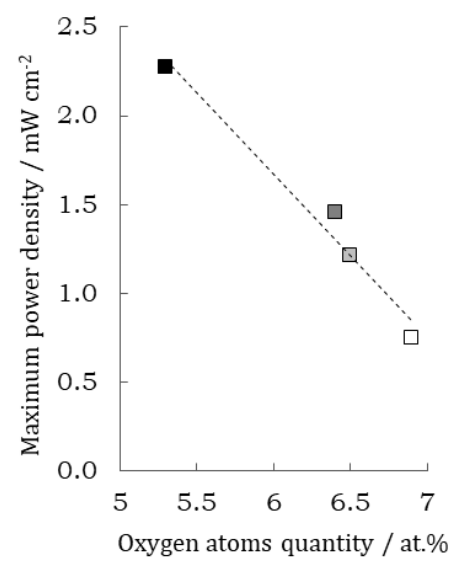

(b)

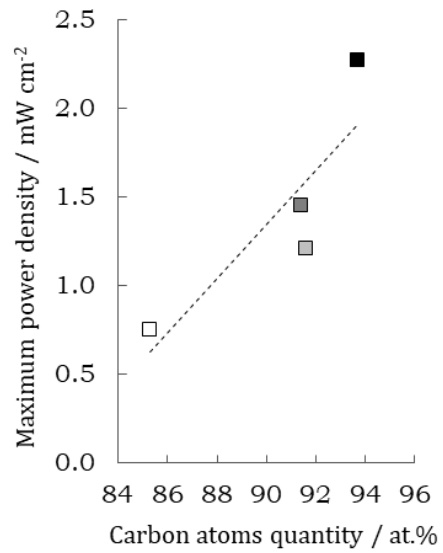

(c)

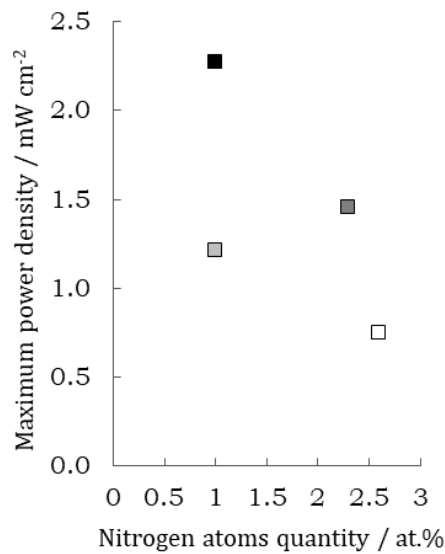

$\mathrm{CE}-750 \square \mathrm{CE}-800 \square \mathrm{CE}-850 \square \mathrm{CE}-900$

\section{Figure 8}

(a)

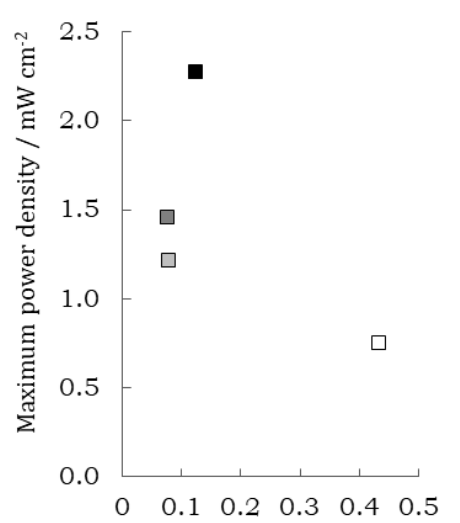

Pyrridinic-N atoms quantity / at.\% (b)

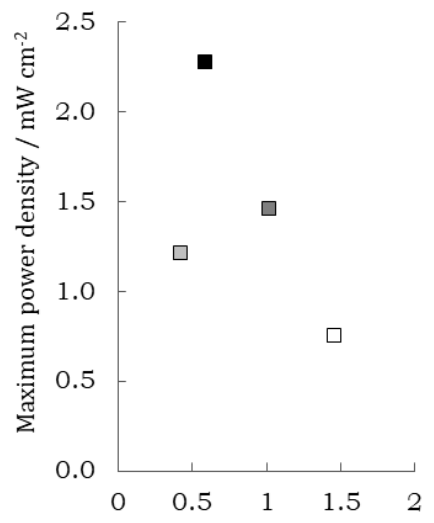

Pyrrolic-N atoms quantity / at.\% (c)

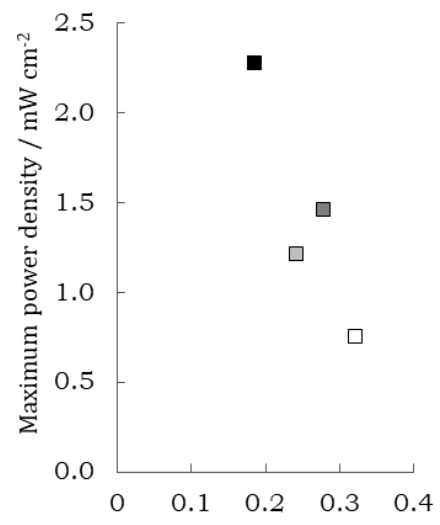

Graphitic-N atoms quantity / at.\%

CE-750 $\square$ CE-800 $\square$ CE-850 $\square$ CE-900

Figure 9 